\title{
Penerapan Model Dynamic Conditional Correlation GARCH Pada Data Saham
}

\author{
Ika Fitriana, $\mathbf{J}^{1^{*}}$, Erna Tri Herdiani ${ }^{2}$, Georgina Maria Tinungki ${ }^{3}$ \\ ${ }^{1,2,3}$ Departemen Statistika, Fakultas MIPA, \\ Universitas Hasanuddin, Makassar, 90245, Indonesia \\ * Corresponding author, email: ikafitria01@gmail.com
}

\begin{abstract}
Stock is one of the popular financial market instruments. Issuing shares is one of the company's choices when deciding to fund a company. The uncertainty of stock prices in the stock market is an important event to be taken into consideration in making a decision by investors so that a model is needed to describe a stock event. GARCH's Dynamic Conditional Correlation (DCC) is a model with a conditional and timedependent variance that describes the dynamics of stock volatility. This study discusses the DCC GARCH model equation which is applied to the $L Q 45$ data. The model obtained for BCA shares $\boldsymbol{Q}_{t}=$ $3393,6877+0,1044 \varepsilon_{i, t-1}^{2}+0,8534 Q_{t-1}$ so it can be concluded that DCC GARCH is more appropriate for BCA shares.
\end{abstract}

Keywords: DCC, GARCH, Stock.

\begin{abstract}
Abstrak
Saham merupakan salah satu instrument pasar keuangan yang popular. Menerbitkan saham merupakan salah satu pilihan perusahaan ketika memutuskan untuk pendanaan perusahaan. Ketidakpastian harga saham dalam pasar saham merupakan suatu kejadian yang penting untuk dijadikan sebuah pertimbangan dalam mengambil sebuah keputusan oleh para investor sehingga sehingga diperlukan model untuk menggambarkan suatu kejadian saham. Dynamic Conditional Correlation (DCC) GARCH merupakan salah satu model dengan varians bersyarat dan bergantung pada waktu yang menggambarkan dinamika volatilitas saham. Pada penelitian ini dibahas tentang persamaan model DCC GARCH yang diaplikasikan pada data LQ 45. Model yang diperoleh untuk saham BCA $\boldsymbol{Q}_{\mathrm{t}}=3393,6877+0,1044 \varepsilon_{i, t-1}^{2}+0,8534 Q_{t-1}$ sehingga dapat disimpulkan bahwa DCC GARCH lebih tepat digunakan untuk saham BCA.
\end{abstract}

Kata Kunci: DCC, GARCH, Saham.

\section{Pendahuluan}

Saham (stock) merupakan salah satu instrument keuangan yang popular. Menerbitkan saham merupakan salah satu pilihan perusahaan ketika memutuskan pendanaan perusahaan. Ketidakpastian harga saham dalam pasar saham merupakan suatu kejadian yang penting untuk dijadikan sebuah pertimbangan dalam mengambil sebuah keputusan oleh para investor.

Dalam investasi saham pengamatan naik turunnya harga saham haruslah menjadi acuan bagi para investor. Hal inilah yang disebut nilai volatilitas yaitu merupakan pengukuran statistik untuk fluktuasi harga suatu sekuritas atau komoditas selama periode tertentu. Semakin tinggi volatilitas, maka semakin tinggi pula tingkat ketidakpastian dari

Estimasi: Journal of Statistics and Its Application

e-ISSN: 2721-3803, p-ISSN: 2721-379X

http://journal.unhas.ac.id/index.php/ESTIMASI 
imbal hasil saham yang dapat diperoleh. Oleh karena itu, pemodelan volatilitas sangatlah diperlukan [1].

Model yang dapat memungkinkan untuk mengatasi hal tersebut adalah Dynamic Conditional Correlation (DCC) GARCH yang memiliki varians bersyarat dan korelasi bergantung terhadap waktu yang menunjukkan dinamika volatilitas saham. Model DCC adalah lanjutan dari model Constant Conditional Correlation (CCC). Matriks korelasi bersyarat dianggap konstan terhadap waktu namun membatasi dalam praktiknya [2]. Oleh sebab itu, berkembang generalisasi model dengan membuat model matriks korelasi bersyarat bergantung terhadap waktu yang disebut $D C C$ [3]. DCC merupakan model yang cukup baik dalam memodelkan analisis deret waktu multivariat karena model DCC menggunakan informasi masa lalu untuk memperkirakan korelasi pada nilai imbal hasil saham sebagai fungsi volatilitas masa lalu.

\section{Material dan Metode}

Data yang digunakan dalam penelitian ini adalah data dari tiga saham LQ 45 yaitu data saham perusahaan bank BCA Tbk, data saham perusahaan perseroan PT. Telekomunikasi Indonesia Tbk, dan data saham perusahaan PT. Indofood Sukses Makmur Tbk. Sumber data yang diambil melalui situs https://finance.yahoo.com. Data yang diambil yaitu data saham harian dari ketiga perusahaan tersebut mulai dari bulan Januari sampai bulan Desember 2017.

Tahapan analisis dalam penelitian ini adalah :

1) Identifikasi data saham dengan statistika deskriptif

2) Memeriksa kestasioneran data

3) Pendugaan parameter model ARIMA

4) Pemilihan model ARIMA terbaik

5) Uji asumsi heterokedastisitas

6) Pendugaan parameter model GARCH

7) Pemilihan model GARCH terbaik

8) Model terbaik dimasukkan ke persamaan model GARCH

9) Kesimpulan

\subsection{Model Autoregressive conditional heterocedasticity (ARCH)}

Model yang dapat digunakan untuk mengatasi varians error yang tidak konstan dalam data time series finansial adalah model ARCH $(p)$ yang diperkenalkan pertama kali oleh Engle pada tahun 1982. Pada model ARCH $(p)$, varians error $\left(\sigma_{t}^{2}\right)$ sangat dipengaruhi oleh error di periode sebelumnya ( $\left.\varepsilon_{t-1}^{2}\right)$ (Wei, 2006) [4].

Untuk lebih spesifikasi, suatu model $\mathrm{ARCH}(p)$ diasumsikan sebagai berikut [5] :

$$
\sigma_{t}^{2}=\alpha_{0}+\alpha_{1} \varepsilon_{t-1}^{2}+\ldots+\alpha_{p} \varepsilon_{t-p}^{2}
$$

Dengan

$$
\varepsilon_{t}=\sigma_{t} x_{t}, x_{t} \sim \text { i.i.d } N\left(\mu, \sigma^{2}\right), \alpha_{0}>0 \text { dan } \alpha_{i} \geq 0 \text { untuk i=0 }
$$


Pada kenyataannya sering diasumsikan mengikuti distribusi normal baku sehingga model $\operatorname{ARCH}(p)$ dapat dicirikan dengan $\varepsilon_{t}=\overline{\sigma_{t}^{2}} x_{t}$ dengan $\sigma_{t}^{2}$ sebagai notasi dari varians bersyarat dalam persamaan diatas. Analisis regresi data panel adalah analisis regresi yang didasarkan pada data panel untuk mengamati hubungan antara satu variabel terikat (dependent variable) dengan satu atau lebih variabel bebas(independent variable).

\subsection{Model Generalized Autoregressive Conditional Heterocedasticity (GARCH)}

Model GARCH dapat dinyatakan sebagai berikut:

$$
\begin{gathered}
r_{t}=\mu_{t}+a_{t} \\
a_{t}=h_{t}^{1 / 2} a_{t} z_{t} \\
h_{t}=\alpha_{0}+\alpha_{1} a_{t-1}^{2}+\cdots+\alpha_{q} a_{t-q}^{2}+\beta_{1} h_{t}+\cdots+\beta_{p} h_{t-p}
\end{gathered}
$$

Persamaan (2) $\mu_{t}$ dapat dimodelkan sebagai deret waktu, mis.model ARIMA, atau hanya sebagai konstanta. Volatilitas dalam (3) dapat ditulis sebagai berikut :

$$
h_{t}=\alpha_{0}+\sum_{i=1}^{q} \alpha_{i} a_{t-i}^{2}+\sum_{j=1}^{P} \beta_{i} h_{t-j}
$$

Pada Persamaan (5), varian bersyarat, $h_{t}$ bervariasi dari waktu ke waktu, tergantung pada pengembalian kuadrat terakhir, $\left\{a_{t-1}^{2}\right\}_{i}^{q}=1$.

\subsection{Model Dynamic Conditional Correlation}

Model DCC GARCH diperkenalkan oleh Engle dan Sheppard. Ide pada model ini adalah matriks kovarian $\boldsymbol{H}_{\boldsymbol{t}}$ dapat dikomposisikan menjadi standar deviasi kondisional $\boldsymbol{D}_{\boldsymbol{t}}$ dan korelasi matriks $\boldsymbol{R}_{\boldsymbol{t}}$. Pada model DCC GARCH kedua model $\boldsymbol{D}_{\boldsymbol{t}}$ dan $\boldsymbol{R}_{\boldsymbol{t}}$ didesain menjadi time varying. Model DCC GARCH pada umumnya didefinisikan sebagai berikut:

$$
\begin{gathered}
r_{t}=\mu_{t}+a_{t} \\
a_{t}=H_{t}^{1 / 2} a_{t} z_{t} \\
H_{t}=D_{t} R_{t} D_{t}
\end{gathered}
$$

Dimana : $\boldsymbol{D}_{\boldsymbol{t}}: \mathrm{n} \times \mathrm{n}$, matriks diagonal dari standard deviasi kondisional dari $\boldsymbol{a}_{\boldsymbol{t}}$ pada waktu ke-t. $\boldsymbol{R}_{\boldsymbol{t}}$ : matriks n x n conditional correlation dari at pada waktu ke-t. Elemen pada matriks diagonal $\boldsymbol{D}_{\boldsymbol{t}}$ adalah standar deviasi dari model univariat GARCH.

$$
\boldsymbol{D}_{\boldsymbol{t}}=\left[\begin{array}{cccc}
\sqrt{h_{1 t}} & 0 & \cdots & 0 \\
0 & \sqrt{h_{2 t}} & \ddots & \vdots \\
\vdots & \ddots & \ddots & 0 \\
0 & \cdots & 0 & \sqrt{h_{n t}}
\end{array}\right]
$$

Dimana $h_{i t}=\alpha i 0+\sum_{q=1}^{Q_{1}} \alpha_{1 q} \alpha_{i, t-q}^{2}+\sum_{p=1}^{P_{1}} \beta_{i p} h_{i, t-p}, \boldsymbol{R}_{\boldsymbol{t}}$ adalah matriks korelasi yang simetris. Elemen $\boldsymbol{H}_{\boldsymbol{t}}=\boldsymbol{D}_{\boldsymbol{t}} \boldsymbol{R}_{\boldsymbol{t}} \boldsymbol{D}_{\boldsymbol{t}}$ adalah :

$$
\left[\boldsymbol{H}_{\boldsymbol{t}}\right]_{i j}=\sqrt{h_{i t} h_{j t} \rho_{i j}}
$$




$$
\boldsymbol{R}_{\boldsymbol{t}}=\left[\begin{array}{ccccc}
1 & \rho_{12, t t} & \rho_{13, t} & \cdots & \rho_{1 n, t} \\
\rho_{12, t} & 1 & \rho_{23, t} & \cdots & \rho_{2 n, t} \\
\rho_{12, t} & \rho_{23, t} & 1 & \ddots & \vdots \\
\vdots & \vdots & \ddots & \ddots & \rho_{n-1, n, t} \\
\rho_{i n, t} & \rho_{2 n, t} & \cdots & \rho_{n-1, n, t} & 1
\end{array}\right]
$$

\section{Hasil dan Diskusi}

LQ 45 adalah saham perusahaan yang tergabung dalam Bursa Efek Indonesia (BEI) yang mencatakan nilai transaksi tertinggi dan rata-rata nilai kapitalisasi pasar tertinggi selama 12 bulan terakhir. Pada data saham BCA rata-rata harga saham penutup sebesar Rp.17.787, harga saham pembuka sebesar Rp.18.280, harga saham tertinggi sebesar Rp.18.416, harga saham terendah sebesar Rp.18.127, harga saham terakhir sebesar Rp.18.275. Pada data saham Indofood rata-rata harga saham penutup sebesar Rp.683.427, harga saham pembuka sebesar Rp.8.221, harga saham tertinggi sebesar Rp. 8.282, harga saham terendah sebesar Rp.8.144, harga saham terakhir sebesar Rp.8.213. Pada data saham Telkom rata-rata harga saham penutup sebesar Rp.3.722, harga saham pembuka sebesar Rp.4.308, harga saham tertinggi sebesar Rp. 4.344, harga saham terendah sebesar Rp.4.276, harga saham terakhir sebesar Rp.4.311. Angka-angka tersebut ditunjukkan secara mendetail pada Tabel 1-3.

Tabel 1. Statistika deskriptif saham BCA

\begin{tabular}{cccccc}
\hline Variabel & $\mathrm{N}$ & Minimum & Maximum & Mean & Variansi \\
\hline$Y$ & 254 & 14.378 & 21.492 & 17.787 & 41.108 \\
\hline$x_{1}$ & 254 & 15.000 & 22.050 & 18.280 & 39.010 \\
\hline$x_{2}$ & 254 & 15.250 & 22.750 & 18.416 & 39.822 \\
\hline$x_{3}$ & 254 & 14.950 & 21.650 & 18.127 & 37.990 \\
\hline$x_{4}$ & 254 & 14.950 & 21.925 & 18.276 & 39.166 \\
\hline
\end{tabular}

Tabel 2. Statistika deskriptif saham Indofood

\begin{tabular}{cccccc}
\hline Variabel & $\mathrm{N}$ & Minimum & Maximum & Mean & Variansi \\
\hline$Y$ & 254 & 7.315 & 8.383 .562 & 683.427 & 528.201 \\
\hline$x_{1}$ & 254 & 7.300 & 8.925 & 8.221 & 13.854 \\
\hline$x_{2}$ & 254 & 7.325 & 9.000 & 8.282 & 13.576 \\
\hline$x_{3}$ & 254 & 7.275 & 8.875 & 8.144 & 13.058 \\
\hline$x_{4}$ & 254 & 7.300 & 8.925 & 8.213 & 14.159 \\
\hline
\end{tabular}


Penerapan Model Dynamic Conditional Correlation GARCH...

Ika Fitriana J, Erna Tri Herdiani, Georgina Maria Tinungki

Tabel 3. Statistika deskriptif saham Telkom

\begin{tabular}{cccccc}
\hline Variabel & $\mathrm{N}$ & Minimum & Maximum & Mean & Variansi \\
\hline$Y$ & 254 & 3.615 & 46.305 & 37.220 & 16.640 \\
\hline$x_{1}$ & 254 & 3.800 & 4.800 & 4.308 & 85.782 \\
\hline$x_{2}$ & 254 & 3.860 & 4.840 & 4.344 & 85.032 \\
\hline$x_{3}$ & 254 & 3.780 & 4.780 & 4.276 & 84.845 \\
\hline$x_{4}$ & 254 & 3.830 & 4.800 & 4.311 & 85.120 \\
\hline
\end{tabular}

Selanjutnya plot data asli ditunjukkan pada Gambar 1 dan terlihat bahwa ketiga saham memiliki mean dan varians yang tidak konstan sehingga perlu dilakukan differencing seperti yang terlihat pada Gambar 2.

Pada Gambar 2 terlihat bahwa setelah dilakukan differencing ordo pertama harga saham memiliki mean yang konstan (stasioner) dan varians yang tidak konstan.

Selanjutnya dilakukan uji heterokedastisitas yang terjadi karena error-term mempunyai koefisien yang tidak sama. Heterokedastisitas merupakan salah satu penyimpangan terhadap asumsi kesamaan varians (homokedastisitas) yang tidak konstan, yaitu varians error bernilai sama untuk setiap kombinasi tetap dari $x_{1}, x_{2}, x_{3}, \ldots, x_{p}$ [6].
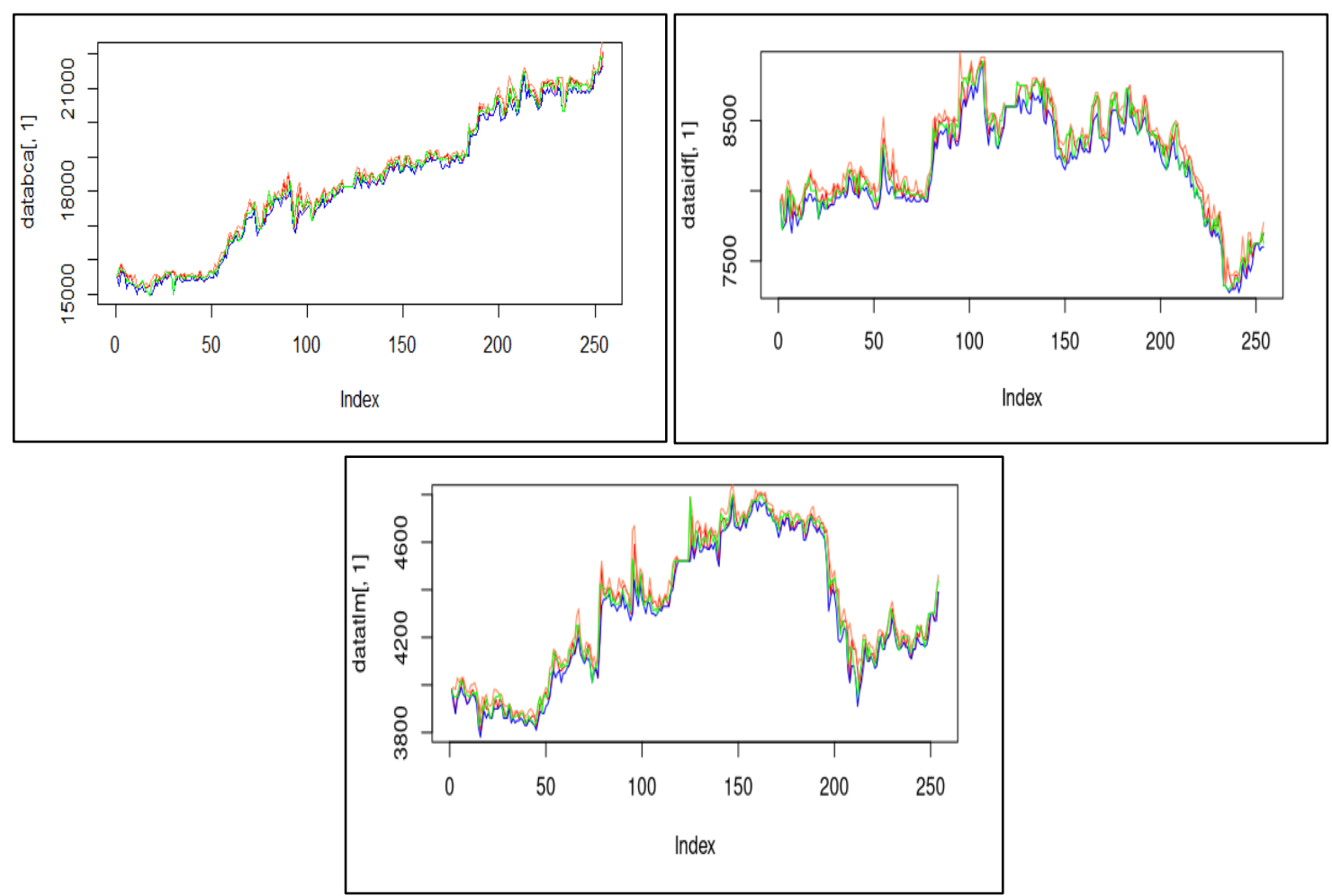

Gambar 1. Plot data asli saham mingguan dari ketiga saham BCA, Indofood dan Telkom tahun 2017 


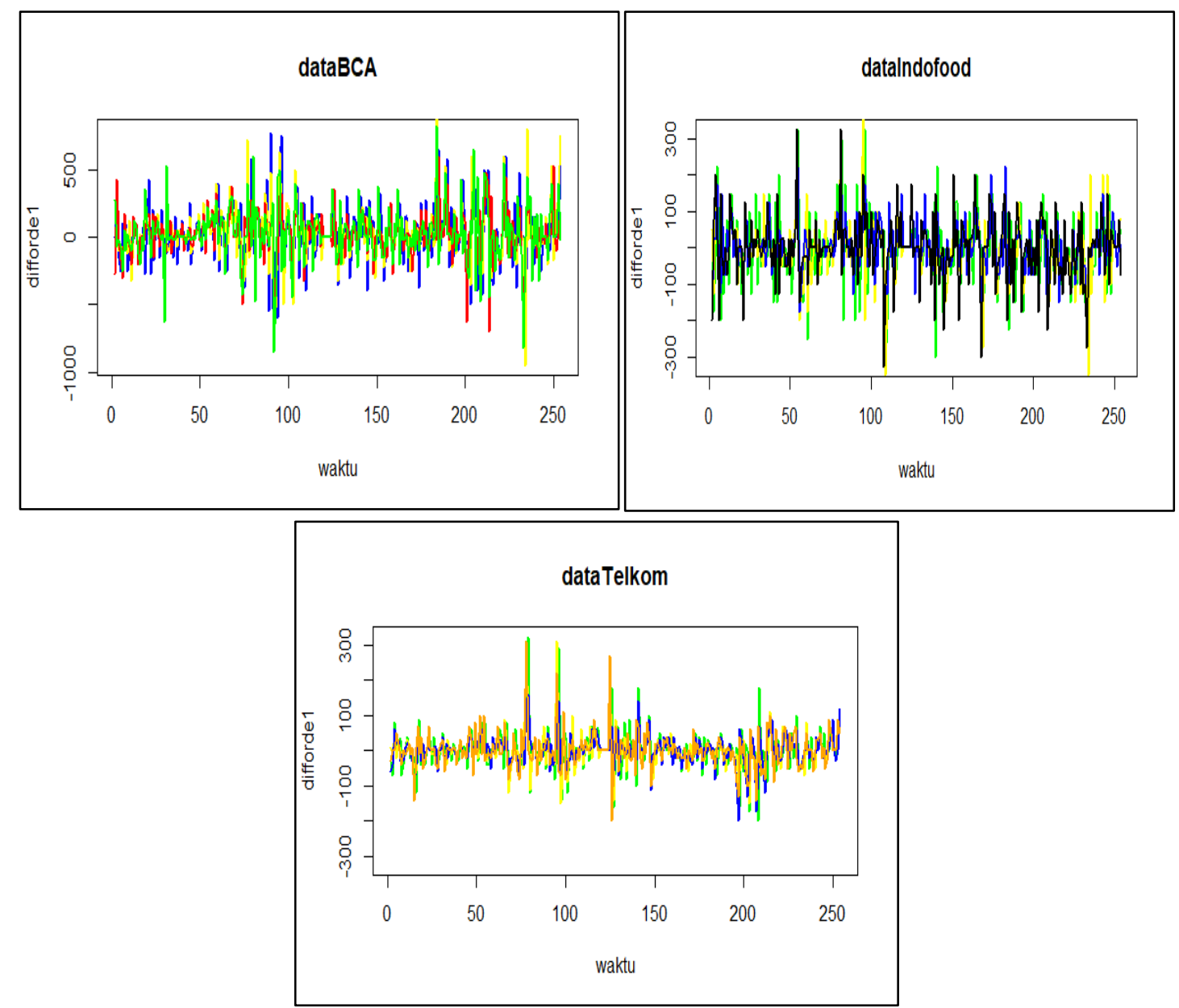

Gambar 2. Plot data diffrencing ordo ke 1 saham mingguan ketiga saham BCA, Indofood dan Telkom.

Tabel 4. Hasil uji heterokedastisitas

\begin{tabular}{ccc}
\hline Data & Model & -value \\
\hline BCA & ARIMA (2.1.3) & 0,924 \\
\hline Indofood & ARIMA (2.1.2) & 0,771 \\
\hline Telkom & ARIMA (1.1.2) & 0,101 \\
\hline
\end{tabular}

Berdasarkan Tabel 4 semua model untuk BCA,Indofood, dan Telkom nilai $p$-value $>\alpha=$ 0,05 maka terima $H_{0}$ sehingga dapat dikatakan bahwa cukup bukti untuk menyatakan terdapat gejala heterokedastisitas pada data harga saham LQ 45. Karena semua model mengandung gejala heterokedastisitas maka sebaiknya digunakan model DCC GARCH.

Model DCC GARCH untuk harga saham BCA adalah sebagai berikut:

$$
\boldsymbol{Q}_{\boldsymbol{t}}=3393,6877+0,1044 \varepsilon_{i, t-1}^{2}+0,8534 Q_{t-1}
$$


Dari model didapatkan nilai konstanta $\mu_{t}$ yaitu 3393,6877 dengan standar error yaitu 54,3429, nilai koefisien $\alpha_{i}$ yaitu 0,1044 dengan standar error yaitu 0,0416 dan nilai koefisien $\beta_{i}$ yaitu 0,8534 dengan standar error sebesar 0,0551 .

Model DCC GARCH untuk harga saham indofood adalah sebagai berikut:

$$
\boldsymbol{Q}_{\boldsymbol{t}}=1995,3087+0,2299 \varepsilon_{i, t-1}^{2}+0,1823 Q_{t-1}
$$

Dari model didapatkan nilai konstanta $\mu_{t}$ yaitu 1995,3087 dengan standar error yaitu 7,8509, nilai koefisien $\alpha_{i}$ yaitu 0,2299 dengan standar error yaitu 0,1823 dan nilai koefisien $\beta_{i}$ yaitu 0,0096 dengan standar error sebesar 0,1552 .

Model DCC GARCH untuk harga saham Telkom adalah sebagai berikut:

$$
\boldsymbol{Q}_{\boldsymbol{t}}=993,1384+0,3001 \varepsilon_{i, t-1}^{2}+0,1717 Q_{t-1}
$$

Dari model didapatkan nilai konstanta $\mu_{t}$ yaitu 993,1384 dengan standar error yaitu 10,7262, nilai koefisien $\alpha_{i}$ yaitu 0,3001 dengan standar error yaitu 0,1823 dan nilai koefisien $\beta_{i}$ yaitu 0.1717 dengan standar error sebesar 0,1734 .

Tabel 5. Standar error data harga saham

\begin{tabular}{lc}
\hline \multicolumn{1}{c}{ Nama Data Saham } & SE \\
\hline BCA & 0,0551 \\
\hline Indofood & 0,1552 \\
\hline Telkom & 0,1734 \\
\hline
\end{tabular}

Berdasarkan Tabel 5 dapat diketahui bahwa standar error dari data harga saham BCA sebesar 0,0551, Indofood 0,1552 dan 0,1734. Dari ketiga data saham tersebut standar error terkecil adalah data harga saham dari BCA sehingga DCC GARCH lebih tepat digunakan pada data harga saham BCA.

\section{Kesimpulan}

Berdasarkan hasil dan pembahasan menunjukkan bahwa DCC GARCH sudah tepat digunakan untuk memodelkan data harga saham pada BCA, Indofood, dan Telkom. Hal ini ditunjukkan oleh nilai standar error yang kecil. Dalam penelitian ini penulis mendapatkan estimasi model pada ketiga harga saham LQ 45 yaitu saham BCA, Indofood dan PT. Telkom pada tahun 2017. Penulis menyarankan untuk melakukan penelitian serupa namun dengan saham yang memenuhi asumsi distribusi normal.

\section{Daftar Pustaka}

[1] Firmansyah. Analisis Volatilitas Harga Kopi Internasional. Jakarta: Usahawan, 2006.

[2] Bollerslev, T. Modelling The Coherence in Short-Run Nominal Exchange Rates: A Multivariate Generalized ARCH Model. Review of Economics and Statistics, 72,498-505, 1990.

[3] Engle, R.F. Dynamic Conditional Correlation - A Simple Class of Multivariate GARCH Model. Journal of Bussiness and Economic, Statistics, 20,339-350, 2002. 
[4] Harris, H. and Sollis, R. Applied Time Series Modelling and Forecasting. Wiley, West Sussex, 2003.

[5] Cryer, J.D. Time Series Analysis. Boston:PWS-Kent Publishing Company, 1986.

[6] Enders,W. Appliied Econometric Time Series. Canada: Jhon Willey \& Sons, Inc, 1995. 